\title{
AVALIAÇÃO DA QUALIDADE DE VIDA DE DOCENTES FISIOTERAPEUTAS DA CIDADE DO SALVADOR / BAHIA ${ }^{1}$
}

\author{
Keith Oliveira Farinha Fisioterapeuta, Graduada pelo Centro \\ Universitário Jorge Amado. \\ Mayara Santos Almeida Fisioterapeuta, Graduada pelo Centro \\ Universitário Jorge Amado. \\ Karen Valadares Trippo Fisioterapeuta, mestre em Gestão e \\ Tecnologias Aplicadas à Educação - \\ Universidade do Estado da Bahia e docente \\ do curso de Fisioterapia do Centro \\ Universitário Jorge Amado.
}

\begin{abstract}
Resumo
Contextualização: Qualidade de Vida $(\mathrm{QV})$ refere-se à percepção do indivíduo de sua posição na vida no contexto da cultura e sistema de valores onde vive e em relação aos seus objetivos, expectativas e preocupações. Atividades exercidas incorretamente e/ou o tempo prolongado em determinadas posturas, podem impactar na QV dos docentes fisioterapeutas. Objetivo: Avaliar e descrever as relações entre as variáveis que influenciam na $\mathrm{QV}$ dos docentes fisioterapeutas da cidade do Salvador/Bahia. Metodologia: Pesquisa descritiva, exploratória, transversal, realizada entre fevereiro e abril/2012. A amostra de conveniência foi composta por 36 voluntários, que responderam uma entrevista elaborada pelas autoras e a Escala de QV (SF-36). Resultados: Todos entrevistados apresentaram média individual/particular da SF-36 maior que 60,81, caracterizando um bom estado geral de QV na população pesquisada. Com o nível de significância de 5\%, os domínios da escala com maior relevância foram "Capacidade Funcional", "Dor", "Limitação por Aspectos Físicos" e "Vitalidade". Conclusão: A significância apontou os domínios "Capacidade Funcional", "Dor", Vitalidade" e "Limitações por Aspectos Físicos" como mais influentes na QV, sendo que as relações feitas entre eles e as "Dores e/ou Desconfortos Oesteomusculares" não se mostraram diretamente proporcionais. A única correlação proporcional foi "Dor e/ou Desconforto Oesteomuscular x Dias em sala", na qual quanto mais dias o docente está em sala, mais ele refere dor. Com base nesses dados, é importante o conhecimento das possíveis repercussões da prática profissional e docente sobre a QV, de forma a permitir ações de sensibilização, prevenção, medidas ergonômicas e de valorização profissional no contexto multidimensional.
\end{abstract}

Palavras-chave: Fisioterapeutas; Docentes; Qualidade de Vida.

\section{EVALUATION OF QUALITY OF LIFE OF THE PHYSIOTHERAPY FACULTY IN SALVADOR CITY, BAHIA}

\begin{abstract}
Background: Quality of Life (QOL) refers to the individual's perception of their position in life in the context of culture and value systems in which they live and in relation to their goals, expectations and concerns. Activities performed incorrectly and / or the time extended under certain postures, may impact on QoL of teachers physiotherapists. Objective: To evaluate and describe relationships between variables that influence QOL teachers physiotherapists of Salvador/Bahia. Methodology: A descriptive, exploratory, cross-sectional, conducted between February and April/2012. The convenience sample consisted of 36 volunteers who answered an interview prepared by the authors and QoL scale (SF-36). Results: All respondents had a mean individual / private SF-36 scores greater than 60.81, featuring a good overall QOL in the population studied. With the significance level of 5\%, the domains of the scale most relevant were "Functional Capacity", "Pain", "Role-Physical" and "Vitality". Conclusion: The significance pointed domains "Functional Capacity", "Pain" Vitality "and" Limitations on Physical Aspects "as more influential in QOL, and relationships made between them and the" Pain and / or Discomfort Oesteomusculares "not showed directly proportional. The only correlation was proportional "Pain and / or Discomfort Oesteomuscular x Days in room", in which the more days the teacher is in the classroom, it refers more pain. Based on these data, it is important to know the possible repercussions of
\end{abstract}

${ }^{1}$ Trabalho de Conclusão de Curso de Fisioterapia do Centro Universitário Jorge Amado - UNIJORGE. 
professional practice and teaching on QOL, to allow awareness raising, prevention, ergonomic measures and professional development in a multidimensional context.

Keywords: Physiotherapists; Teachers; Quality of Life.

\section{CONTEXTUALIZAÇÃO}

A docência é uma arte regida pelo movimento, novas experiências e contextos, em novos tempos e lugares, gerando novas necessidades e interações. Caracteriza-se como um processo não estático, e que sofre constantes mutações. Segundo a Secretaria de Educação Superior (SESU), o profissional da atualidade, para atender às demandas desta sociedade capitalista, deverá possuir uma formação crítica, com atitudes questionadoras e criativas, sendo acima de tudo íntegro, honesto e respeitoso às leis que o regem. Desta forma, tendo apenas o próprio corpo como o centro do trabalho acadêmico, é visível o impacto sobre a qualidade de vida (QV), sofrido pelo profissional, no exercício das suas atividades. ${ }^{(1)}$

No contexto atual do mercado, este profissional deve suprir a necessidade crescente da produtividade para alcançar o padrão de acumulação do capital, o que significa intensificar a exploração da força do trabalho, que muitas vezes implica no aumento desmedido da carga horária e da sobrecarga corporal do mesmo. ${ }^{(2)}$

No caso do profissional fisioterapeuta, foco deste trabalho, o mesmo pode atuar em hospitais, clínicas, ambulatórios, consultórios, centros de reabilitação, programas institucionais, ações básicas de saúde, fisioterapia do trabalho (empresa), vigilância sanitária, na indústria de equipamentos de uso fisioterapêutico, pesquisa, supervisão, direção e coordenação de cursos, como também na docência. Pode ser observado ainda, na prática diária, que muitos fisioterapeutas docentes atuam simultaneamente em outros locais, prestando atendimento à população, associando outras tarefas profissionais à docência. $^{(3,1)}$

Assim, associado ao amplo campo de atuação e, muitas vezes, à baixa remuneração, os fisioterapeutas geralmente trabalham em mais de dois locais com o objetivo de acréscimo da renda salarial, muitas vezes negligenciando a sua própria saúde, apesar desta ser o principal enfoque da profissão. Alguns destes fisioterapeutas escolhem atuar na área de maior afinidade, além de ingressarem na área acadêmica. De acordo com artigos encontrados, ${ }^{(4)}$ as possíveis repercussões da dupla jornada de 
trabalho são diversas, o que inclui a sobrecarga psicológica e a fadiga física ou burnout, que pode ser detalhada por uma síndrome caracterizada por tempo insuficiente para lazer, descanso, horas de sono e alimentação.

Segundo alguns autores, ${ }^{(5)}$ a fisioterapia é uma ocupação estressante, pois demanda esforço físico para tarefas como levantamento, inclinação, flexão e rotação do tronco, tempo prolongado em posturas inadequadas e manutenção do ortostatismo. De acordo com os mesmos autores, a associação desses fatores pode ser responsável pela origem de distúrbios relacionados ao trabalho, principalmente no que diz respeito à dor lombar, nos membros inferiores, em mãos, punhos e polegares, sendo mais acometidos aqueles fisioterapeutas que atuam nas áreas de neurologia, ortopedia, reumatologia, cardiopneumologia, geriatria e hidroterapia. Tendo em vista que os docentes formados em fisioterapia além de atuarem em sala de aula, passam parte do seu tempo prestando serviços fisioterapêuticos à comunidade, a junção das atividades como professores e como fisioterapeutas, pode ser um indicador de futuros problemas osteomusculares e de repercussões potencialmente negativas na qualidade de vida.

Além disso, no caso do docente, a associação entre as tarefas burocráticas, má remuneração, falta de autonomia e muitas vezes relações conflitantes entre este e os discentes, levam a um quadro depreciativo do contexto biopsicossocial deste profissional, impactando de forma grave na qualidade de vida. De acordo com Martins, ${ }^{(6)}$ a Qualidade de Vida no trabalho depende de inúmeras variáveis, o que dificulta a sua manutenção a partir do momento em que é obtida. Sabe-se que a realização pessoal está diretamente ligada à esfera profissional, logo, a insatisfação e a alienação no trabalho interferem nas demais vertentes da vida. ${ }^{(7,8)}$

O impacto na saúde física e mental leva a alterações negativas na qualidade de vida, a qual é definida pela Organização Mundial de Saúde como “a percepção do indivíduo de sua posição na vida no contexto da cultura e sistema de valores nos quais ele vive e em relação aos seus objetivos, expectativas, padrões e preocupações". ${ }^{(9)}$ Podese observar, então, que a prática inadequada da atividade exercida resulta na presença de sintomas osteomusculares e pode comprometer a qualidade de vida e o estado de saúde dos professores, inclusive dos docentes fisioterapeutas.

Diante deste contexto, no qual o profissional fisioterapeuta tem uma ocupação que gera estresse físico e mental, associando-a à docência, onde há sobrecargas 
emocionais e musculoesqueléticas, onde ambas são pouco valorizadas financeiramente, observamos duas ocupações com potencial impacto sobre a qualidade de vida desses indivíduos. Com base na relevância da temática aqui apresentada e já que o docente fisioterapeuta é raramente abordado nos estudos de qualidade de vida, o que denota uma lacuna científica, tornam-se necessários estudos na área. Nesse sentido, abordar a qualidade de vida destes profissionais poderá fornecer informações para o entendimento da saúde física e psicossocial dessa população em específico, de forma a permitir ações de sensibilização, prevenção, medidas ergonômicas e de valorização profissional no contexto multidimensional.

Logo, o objetivo deste trabalho é avaliar e descrever os dados coletados pelas Escala SF-36 e pela Entrevista Semiestruturada e cruzar pontos específicos de cada um destes instrumentos, os quais apontarem relevância aos autores, para busca de correlações significativas, as quais, podem vir a influenciar na qualidade de vida dos docentes fisioterapeutas da cidade do Salvador/Bahia. Buscamos isto através de um estudo de campo descritivo e transversal.

\section{METODOLOGIA}

Caracterizou-se por uma pesquisa de campo, descritiva, exploratória, do tipo transversal, com o objetivo de avaliar e descrever as relações entre as variáveis que influenciam na qualidade de vida dos profissionais formados em Fisioterapia e que atuavam como docentes na cidade do Salvador/Bahia no período da coleta dos dados.

Sua fundamentação teórica foi realizada através de pesquisas bibliográficas com base em artigos publicados no período de 2001 à 2011, salvo artigo do ano de 1999 que traz o conceito de Qualidade de Vida, devido sua relevância histórica. Os artigos científicos foram pesquisados nas bases de dados Lilacs, Scielo, Pubmed, Medline e Bireme. Como unitermos foram utilizadas as seguintes palavras-chave: fisioterapeutas, docentes e qualidade de vida, bem como seus correlatos em inglês e espanhol.

A fase exploratória da pesquisa foi iniciada após aprovação do Comitê de Ética em Pesquisa (CEP), atendendo à Resolução 196/96 do Conselho Nacional de Ética em Pesquisa (CONEP) em virtude da necessidade de contato com seres humanos; porém, 
não houve qualquer procedimento de caráter invasivo ou de tratamento. $\mathrm{O}$ projeto foi aprovado pelo CEP da UNIFACS sob o protocolo 04.11.57.

Como universo de pesquisa, foram escolhidos fisioterapeutas formados e que atuassem como docentes nas Instituições de Ensino Superior da cidade do Salvador/Bahia, as quais autorizaram antecipadamente a coleta de dados em suas dependências, mediante apresentação da Carta de Solicitação, o que torna essa uma amostra de conveniência. Todos os docentes entrevistados cumpriram com os seguintes critérios de inclusão, ter formação em Fisioterapia e atuar na docência no período da coleta de dados.

Foram utilizados como instrumentos da pesquisa uma entrevista semiestruturada, desenvolvida pelas autoras, e o questionário de QV SF-36, onde posteriormente, ambos os materiais tiveram suas informações cruzadas para obtenção de correlações relevantes descritas de forma detalhada nos resultados. No início de fevereiro de 2012, foi aplicado um estudo-piloto para calibração dos instrumentos de pesquisa. A coleta de dados foi, então, realizada após a conclusão desta etapa, entre fevereiro e abril de 2012.

$\mathrm{Na}$ fase da coleta dos dados, os voluntários foram informados sobre a temática da pesquisa e convidados a participarem. Após o aceite, assinaram o Termo de Consentimento Livre e Esclarecido (TCLE) e, imediatamente a seguir, era realizada a Entrevista Semiestruturada, a qual continha questões sobre dados pessoais como nome, idade, sexo, tempo de formação, tempo de atuação como docente, carga horária/aula teórica e prática (compreendida por aulas práticas e estágio supervisionado), quantidade de Instituições de Ensino Superior que leciona, quantos dias o profissional atua como docente durante a semana, o número de disciplinas que leciona, atuação extraclasse, carga horária das demais atividades e dias que a exerce, área em que atua, queixas de dores/desconfortos osteomusculares e doença osteomuscular com diagnóstico clínico com base nas informações prestadas pelos participantes.

Em seguida, cada participante respondeu individualmente ao Questionário SF-36 - Medical Outcomes Study 36-item Short Form Health Survey, validada no Brasil em 1999. Este é composto por 36 itens, que contemplam capacidade funcional, aspectos físicos, dor, estado geral de saúde, vitalidade, aspectos sociais, aspectos emocionais e saúde mental. A pontuação final (escore) varia entre 0 a 100, no qual zero corresponde ao pior estado de saúde e 100 ao melhor estado de saúde. ${ }^{(10)}$ Os autores não delimitam 
uma pontuação corte para referirem-se à pior estado de saúde ou à melhor estado de saúde, apenas a aproximação do escore ao 100 ou ao 0. Sendo assim, para otimizar a classificação da QV baseada nos escores encontrados, foi considerado, para este trabalho, que uma pontuação de até 50 estava relacionada ao "pior estado"; já os valores acima de 51 foram conceituados como "melhor estado".

As variáveis independentes consideradas foram: carga horária de trabalho em sala de aula, carga horária de trabalho extraclasse e as atividades exercidas além do ambiente acadêmico, assim como a quantidade de instituições onde trabalha e se sua atuação acadêmica é prática ou teórica, ou mesmo ambas. Já as variáveis dependentes foram determinadas pelos domínios contemplados na Escala SF-36. As variáveis cruzadas para obtenção de correlações que tivessem relevância, foram "Anos em Sala de aula X Dor e/ou Desconforto Osteomuscular", "Carga Horária Teórica (CHt) x Dor e/ou Desconforto Oesteomuscular”, “Carga Horária Prática (CHp) x Dor e/ou Desconforto Osteomuscular", "Limitação por Aspectos Emocionais (LAE) x Dor e Desconforto Osteomuscular”, "Capacidade Funcional (CF) x Dor e Desconforto Osteomuscular", "Limitação por Aspectos Físicos (LAF) x Dor e Desconforto Osteomuscular", "Vitalidade x Dor e Desconforto Osteomuscular" e "Dias em Sala x Dor e/ou Desconforto Osteomuscular.

Para análise dos dados foi utilizado o programa SPSS, versão 12.0. Também foi utilizada a Correlação de Pearson $(P)$ com o objetivo de comparar os domínios da escala SF-36 aos dados coletados na entrevista semiestruturada. $O$ valor de $P$ significativo neste trabalho foi de -0,351, o que indica uma correlação moderada. O nível de significância considerado foi de $5 \%$. Os resultados dos escores individuais referentes à escala SF-36 foram enviados através de correio eletrônico aos voluntários, a fim de promover uma devolutiva aos participantes. A análise descritiva foi feita através das médias de cada pergunta presente no Questionário Semi-estruturado.

\section{RESULTADOS}

Na cidade do Salvador/Bahia, existiam no momento da coleta de dados, um total de 10 instituições de ensino superior, as quais, apenas três delas, permitiram a aplicação desta pesquisa em suas dependências, mediante uma carta convite. As demais 
instituições também não forneceram dados quanto ao seu corpo docente. Nas três instituições colaboradoras, houve um total de 36 voluntários, dos quais 20 indivíduos $(52,8 \%)$ constituíram a população feminina e $16(47,2 \%)$ a população masculina. A idade média foi de 36,2, sendo que dois (5,6\%) encaixavam-se na faixa etária de 20-25 anos, seis $(16,7 \%)$ de $26-30$ anos, onze $(30,6 \%)$ de $31-35$ anos, oito $(22,2 \%)$ de $36-40$ anos, quatro $(11,1 \%)$ de $41-45$ anos, quatro $(11,1 \%)$ de $46-50$ anos, zero de 51-55 anos, e um $(2,8 \%)$ de $56-60$ anos.

Tratando-se do tempo que os voluntários têm como fisioterapeutas, quatro $(11,1 \%)$ participantes têm de 0-5 anos de profissão, onze $(30,6 \%)$ de 6-10 anos, onze $(30,6 \%)$ de 11-15 anos, seis $(16,7 \%)$ de 16-20 anos, dois (5,6\%) de 21-25 anos, um $(2,8 \%)$ de 26-30 anos e, um (2,8\%) de 31-35 anos como fisioterapeutas. Quanto aos anos lecionando, a maior porcentagem foi a de 16,67\%, representada por 6 indivíduos que trabalham há 8 anos como docentes. Esses dados podem ser visualizados no Gráfico 1 abaixo.

Gráfico 1 - Anos lecionando pelos docentes / fisioterapeutas pesquisados

ANOS LECIONANDO

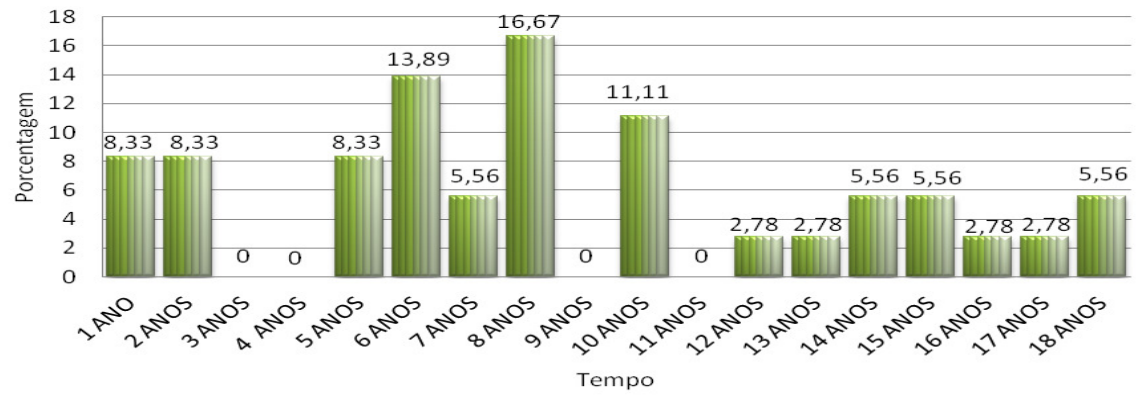

Fonte: Dados dos autores.

Com relação à Carga Horária/Aula Teórica $(\mathrm{CHt})$, compreendida por hora/aula de 50 minutos, tempo padronizado nas instituições de ensino superior avaliadas, podemos observar no gráfico 2 que cinco $(13,9 \%)$ docentes relataram dispor de cinco horas (semanais) de hora/aula teórica, dez $(27,8 \%)$ de dez horas/aula, três $(8,3 \%)$ de quinze horas/aula, nove $(25 \%)$ de vinte horas/aula, um $(2,8 \%)$ de vinte e cinco horas/aula, dois $(5,6 \%)$ de trinta horas/aula, um $(2,8 \%)$ de trinta e cinco horas/aula, três $(8,3 \%)$ de quarenta horas/aula, um $(2,8 \%)$ de cinquenta horas/aula e, um $(2,8 \%)$ acima de cinquenta e cinco horas/aula. E com relação à Carga Horária/Aula Prática $(\mathrm{CHp})$, 
definida por aulas práticas e supervisão de estágio, sete $(19,4 \%)$ professores relataram não ter $\mathrm{CHp}$, seis $(16,7 \%)$ têm cinco horas (semanais) de $\mathrm{CHp}$, nove (25\%) têm dez horas, quatro $(11,1 \%)$ têm quinze horas, sete $(19,4 \%)$ têm vinte horas, um $(2,8 \%)$ têm trinta horas, um (2,8\%) têm trinta e cinco horas e, um (2,8\%), têm quarenta horas.

Gráfico 2 - Carga Horária Semanal compreendida por hora/aula teórica e prática como docente

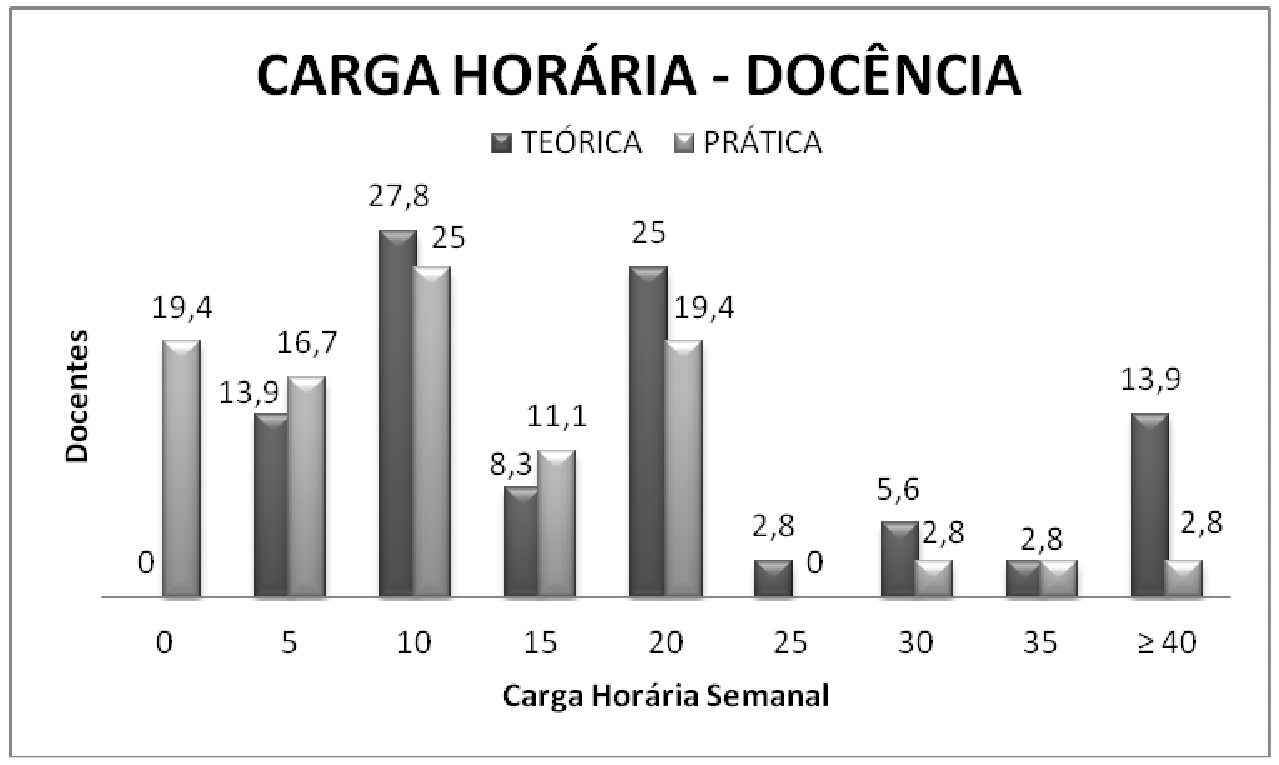

Fonte: Dados dos autores.

No quesito relacionado à quantidade de Instituições de Ensino Superior em que lecionavam, quinze $(41,7 \%)$ voluntários são vinculados a apenas um local, dez $(27,8 \%)$ a dois locais, nove (25\%) a três locais e dois $(5,6 \%)$ a quatro locais. A partir da questão supracitada, dois $(5,6 \%)$ participantes relataram ministrar aula apenas um dia da semana, três $(8,3 \%)$ dois dias, seis $(16,7 \%)$ três dias, sete $(19,4 \%)$ quatro dias, dezesseis $(44,4 \%)$ cinco dias e, dois $(5,6 \%)$ seis dias da semana. Tratando-se da quantidade de disciplinas lecionadas, cinco $(13,9 \%)$ participantes afirmaram ensinar uma disciplina, sete $(19,4 \%)$ duas, dez $(27,8 \%)$ três, sete $(19,4 \%)$ quatro, quatro $(11,1 \%)$ cinco e, três $(8,3 \%)$ seis matérias.

Quando questionados sobre a atuação fora da sala de aula, cinco $(13,9 \%)$ voluntários responderam apenas trabalharem como docentes do ensino superior, nove (25\%) atuam em Clínica, um (2,8\%) em Ambulatório, quatro $(11,1 \%)$ em Hospital, sete $(19,4 \%)$ em Gestão, três $(8,3 \%)$ em Atendimento Domiciliário, um (2,8\%) em Clínica e em Gestão, quatro $(11,1 \%)$ em Clínica e Atendimento Domiciliário, um $(2,8 \%)$ em 
Gestão e Atendimento Domiciliário e, um (2,8\%) em Clínica, Gestão e Atendimento Domiciliário. Dos 31 voluntários que trabalham em outros locais além da(s) Instituição(ões) de Ensino Superior, cinco $(13,9 \%)$ têm carga horária de cinco horas semanais $(\mathrm{hr} / \mathrm{sem})$, cinco $(13,9 \%)$ de $10 \mathrm{hr} / \mathrm{sem}$, três $(8,3 \%) 15 \mathrm{hr} / \mathrm{sem}$, cinco $(13,9 \%)$ de $20 \mathrm{hr} / \mathrm{sem}$, três $(8,3 \%) 25 \mathrm{hr} / \mathrm{sem}$, cinco $(13,9 \%)$ de $30 \mathrm{hr} / \mathrm{sem}$, um $(2,8 \%) 45 \mathrm{hr} / \mathrm{sem}$, um $(2,8 \%) 50 \mathrm{hr} / \mathrm{sem}$, dois $(5,6 \%) 60 \mathrm{hr} / \mathrm{sem}$ e, um $(2,8 \%)$ de $70 \mathrm{hr} / \mathrm{sem}$. Esses dados podem ser melhor observado no Gráfico 3.

Gráfico 3 - Carga Horária de outras atividades além da docência

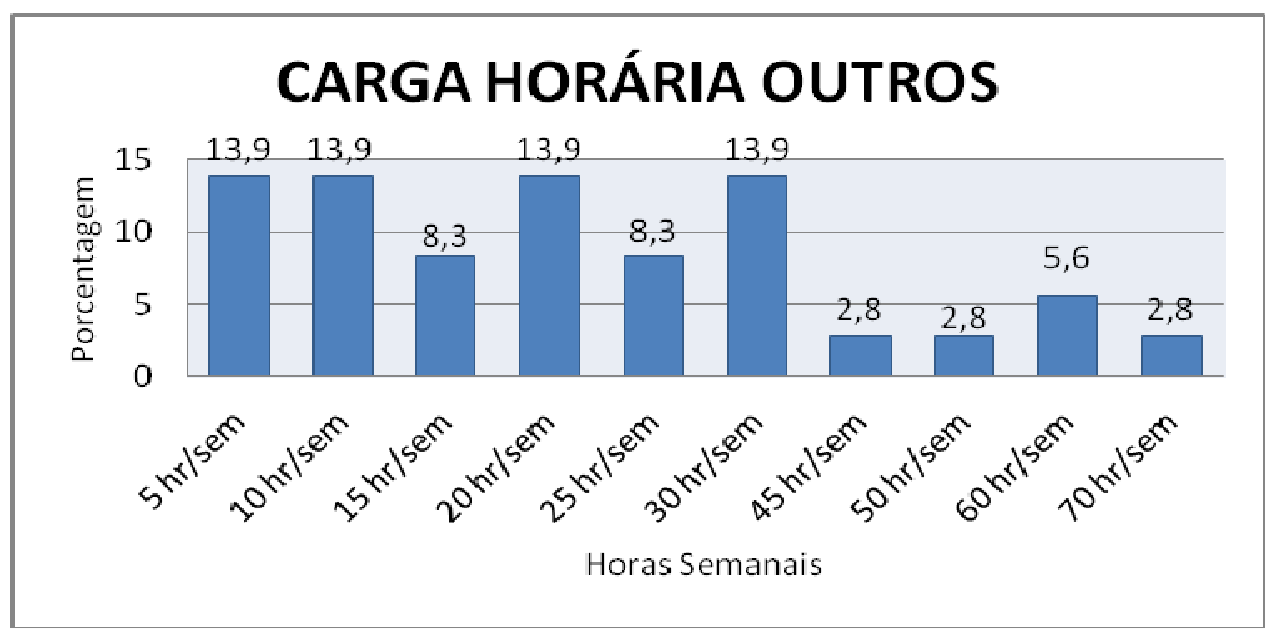

Fonte: Dados dos autores.

Então, além da docência, 31 (86,10\%) voluntários trabalham também em outras áreas da Fisioterapia. Destes 31 indivíduos, doze (46,8\%) trabalham em "Outros" (Terapias Holísticas, Acupuntura, RPG - Reeducação Postural Global, Saúde da Mulher, Saúde na Comunidade, Ortotrauma e Geriatria), cinco $(13,9 \%)$ Gestão, três $(8,4 \%)$ Neurologia, três $(8,4 \%)$ Fisioterapia Aquática, três $(8,3 \%)$ trabalham em UTI, dois $(5,8 \%)$ Ortopedia, dois $(5,6 \%)$ Dermato-funcional, um $(2,8 \%)$ em Pediatria, como é apresentado no Gráfico 4. 


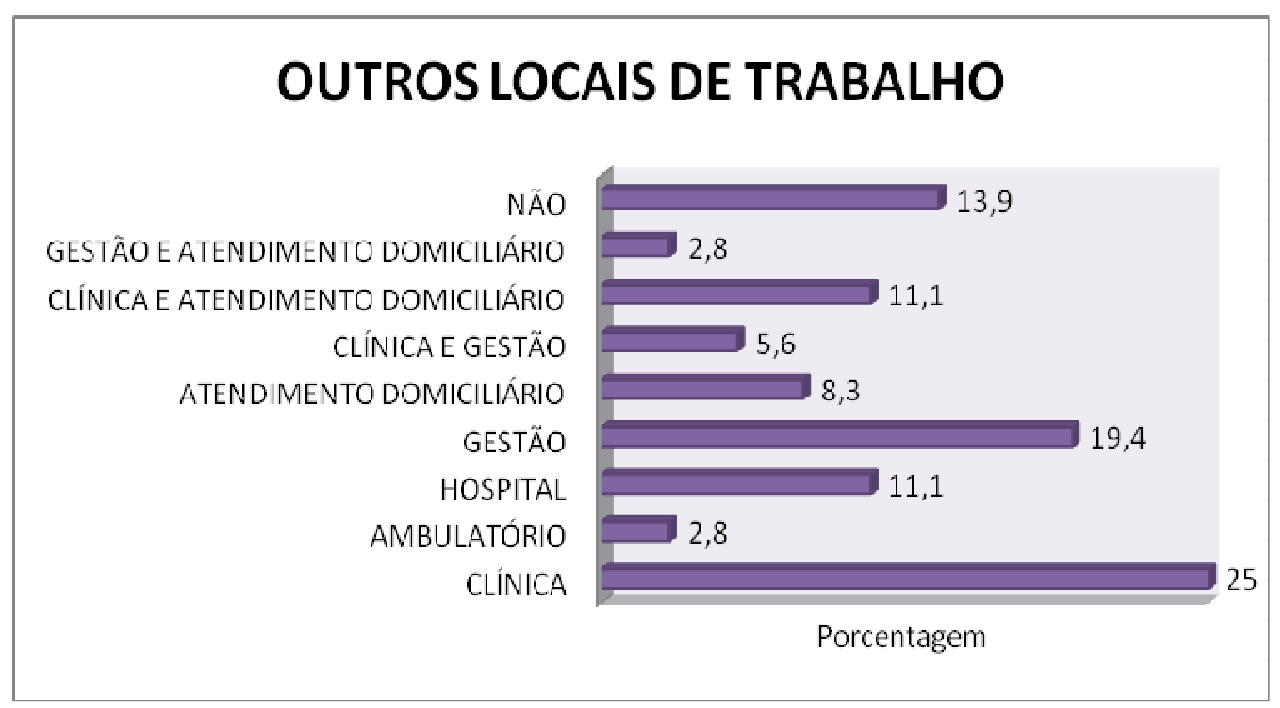

Fonte: Dados dos autores.

Dos 36 voluntários, dezesseis $(72,2 \%)$ relataram não apresentar doença muscular ou óssea diagnosticada, e dez $(27,8 \%)$ confirmaram a presença de um diagnóstico clínico de alteração musculoesquelética. Dentre esses últimos, três $(8,4 \%)$ apresentam hérnia de disco, e as patologias condromalácia, desvio postural, fasceíte plantar, lesão no ligamento cruzado anterior (LCA), lesão no menisco, miosite ossificante e Síndrome de Bertolotti / Lombarização do Sacro, foram de apenas um participante para cada patologia $(2,8 \%)$.

Vinte e três voluntários $(63,9 \%)$ queixaram-se de dor e/ou desconforto osteomuscular, associada ou não à doença prévia, sendo que as regiões mais referidas pela população supracitada foram: quatro $(17,4 \%)$ relataram dor na região Lombar associada ao Ombro, três (13\%) apenas no Ombro, três (13\%) apenas na Lombar e dois $(8,7 \%)$ no Joelho e Ombro. As regiões da cervical, cervical associada ao ombro, cervical associada à lombar, cervical associada aos MMII, coluna vertebral, joelhos, joelhos e cervical, lombar e quadril, pé e região toracolombar, apresentaram uma porcentagem de 4,3\% cada quanto à presença de sintomatologia álgica, o que corresponde a apenas um indivíduo para cada região álgica citada.

Em relação à SF-36, a qual apresenta oito domínios, o escore final de 0 equivale ao "Pior Estado de Saúde" e o de 100 corresponde ao "Melhor Estado de Saúde", todos os avaliados apresentaram um escore total individual/particular maior que 60,81. Com o nível de significância de 5\%, foi encontrada uma diferença com relação aos escores entre o grupo que sente dor e o que não sente nos domínios "Capacidade Funcional", 
"Dor", "Vitalidade" e "Aspectos Físicos", ou seja, os domínios supracitados demonstraram escores positivos e significativos nos grupos de indivíduos que referiram dor e/ou desconforto osteomuscular, apesar destas sintomatologias.

Com relação ao domínio “Capacidade Funcional”, obteve-se um escore médio de 91,52, com o valor mínimo obtido de 65 e o máximo de 100, significando boa QV. Dos entrevistados, $17(47,2 \%)$ voluntários apresentaram o escore de 100, três $(8,3 \%)$ apresentaram 95, cinco $(8,3 \%)$ 90, dois $(5,6 \%) 85$, quatro $(11,1 \%) 80$, três $(8,3 \%) 75$, e dois $(5,6 \%)$ 65. Então, os voluntários possuem entre "bom e melhor estado de saúde" relacionado ao quesito supracitado.

De maneira semelhante, no que se refere ao aspecto "Dor", que obteve uma média de 76,69, com valor mínimo de 31 e máximo de 100, dez (27,8\%) participantes obtiveram 100 no escore final da SF-36, nove $(25 \%)$ 84, dois $(5,6 \%) 74$, cinco $(13,9 \%)$ 72 , três $(8,3 \%) 62$, um $(2,8 \%) 52$, dois $(5,6 \%) 51$ da pontuação referente às questões sobre dor, o que significa "melhor estado de saúde". Apenas dois voluntários $(5,6 \%)$ atingiram 41, um $(2,8 \%) 31$ e, um (2,8\%) 10, o que equivale ao "pior estado de saúde".

Na questão "Vitalidade", a pontuação mais alta obtida foi de 85 por cinco $(13,9 \%)$ participantes, cinco $(13,9 \%)$ atingiram 80 , oito $(22,2 \%) 75$, dois $(5,6 \%) 70$, dois $(5,6 \%) 65$, três $(8,3 \%) 60$, três $(8,3 \%) 55$, três $(8,3 \%) 50$ pontos. Apenas cinco $(13,9 \%)$ participantes obtiveram pontuações que indicam "pior estado de saúde", o que levou a média deste escore, em particular, ser a mais baixa, representando 67,50, com valor mínimo de 35 e máximo de 95.

Nas "Limitações por Aspectos Físicos", 23 participantes (63,9\%) obtiveram escore igual a 100, oito $(22,2 \%) 75$, e um (2,8\%) 50, com "melhor estado de saúde". Três $(8,3 \%)$ participantes obtiveram pontuação de 25 , e um $(2,8)$ obteve zero de pontuação, o que repercute negativamente sobre o estado de saúde do indivíduo. Foi obtida uma média de 85,41 pontos, com valor mínimo de 0 e máximo de 100 .

No "Estado Geral de Saúde", a média encontrada foi de 82,36 pontos, com valor mínimo de 57 e máximo de 100 . Três $(8,3 \%)$ voluntários atingiram a pontuação de 100 , dois $(5,6 \%) 95$, três $(8,3 \%) 92$, um $(2,8 \%)$ ) quatro $(11,1 \%) 82$, um $(2,8 \%) 80$, seis $(16,7 \%) 77$, dois $(5,6 \%) 72$, quatro $(11,1 \%) 67$, um $(2,8 \%)$ 62, e um $(2,8 \%)$ 57. Sendo assim, os voluntários possuem entre "bom e melhor estado de saúde". 
No domínio "Saúde Mental", a média encontrada foi de 79,52 pontos, com valor mínimo de 56 e máximo de 96 , onde cinco $(13,9 \%)$ voluntários atingiram o escore de 96 , quatro $(11,1 \%) 92$, quatro $(11,1 \%) 88$, três $(8,3 \%) 84$, dois $(5,6 \%) 80$, cinco $(13,9 \%) 76$, um $(2,8 \%) 75$, quatro $(11,1 \%) 72$, dois $(5,6 \%) 68$, quatro $(11,1 \%) 64$ e dois $(5,6 \%) 56$. Novamente os escores apontam para o fato de que os voluntários possuem entre "bom e melhor estado de saúde" quando relacionado a este quesito. No domínio "Aspectos Sociais", a média encontrada foi de 80,90 pontos, com valor mínimo de 37,5 e máximo de 100 . Nesta questão correspondente, 13 pessoas $(36,1 \%)$ obtiveram 100 pontos, cinco $(13,9 \%)$ 87,5, cinco $(13,9 \%) 75$, nove $(25 \%)$ 62,5, um $(2,8 \%) 50$, e apenas três $(8,3 \%) 37,5$.

Já no quesito "Limitações por Aspectos Emocionais", 27 voluntários (75\%) atingiram um escore de 100, um (2,8\%) 66,6, cinco $(13,9 \%) 33,3$, e três $(8,3 \%)$ obtiveram pontuação zero para as questões referentes ao domínio supracitado. Nota-se que oito $(22,2 \%)$ participantes obtiveram resultados negativos quanto ao escore do domínio "Limitação por Aspectos Emocionais" (LAE); o que, no contexto geral, pode impactar de maneira desfavorável na Qualidade de Vida do participante. Tal fato contribuiu para uma média de 84,25 pontos, com valor mínimo de 0 e máximo de 100 . Este domínio ficou na margem da significância adotada pelo presente trabalho, alcançando o nível de 6\%, sendo 5\% a significância adotada no presente trabalho.

Os dados referentes às médias, desvios-padrão, valores mínimos e máximos de cada domínio específico da SF-36 podem ser melhor visualizados na Tabela 1.

Tabela 1 - Valores obtidos para cada componente do questionário SF-36 


\begin{tabular}{|c|c|c|c|c|}
\hline Componentes & Média & Desvio-Padrão & Mínimo & Máximo \\
\hline Capacidade Funcional & 91,52 & 10,62 & 65 & 100 \\
\hline Dor & 76,69 & 20,07 & 31 & 100 \\
\hline Vitalidade & 67,50 & 14,75 & 35 & 95 \\
\hline Limitações por Aspectos Físicos & 85,41 & 25,14 & 0 & 100 \\
\hline Estado Geral de Saúde & 82,36 & 10,18 & 57 & 100 \\
\hline Saúde Mental & 79,52 & 11,92 & 56 & 96 \\
\hline Aspectos Sociais & 80,90 & 19,95 & 37,5 & 100 \\
\hline Limitações por Aspectos Emocionais & 84,25 & 28,24 & 0 & 100 \\
\hline
\end{tabular}

No que se refere aos dados colhidos na entrevista semiestruturada aplicada, usou-se a Correlação de Pearson para correlacionar “Anos em Sala de aula X Dor e/ou Desconforto Osteomuscular", não sendo observado qualquer relação diretamente ou inversamente proporcional entre si. O $P$ encontrado nesta correlação foi abaixo de 0,30 , o que caracteriza esta uma correlação fraca. O mesmo pôde ser observado quando comparou-se as variáveis "Carga Horária Teórica (CHt) x Dor e/ou Desconforto Oesteomuscular", "Carga Horária Prática (CHp) x Dor e/ou Desconforto Osteomuscular", "Anos em sala de Aula X Dor e/ou Desconforto Osteomuscular”, bem como "Limitação por Aspectos Emocionais (LAE) x Dor e Desconforto Osteomuscular", "Capacidade Funcional (CF) x Dor e Desconforto Osteomuscular", "Limitação por Aspectos Físicos (LAF) x Dor e Desconforto Osteomuscular" e "Vitalidade x Dor e Desconforto Osteomuscular".

Entretanto, com $P=0,351$ foi evidenciado que há uma relação diretamente proporcional, segundo os resultados encontrados, entre as variáveis "Dias em Sala $\mathbf{x}$ Dor e/ou Desconforto Osteomuscular”, que é visualizada na Tabela 2. Estes dados apresentaram uma correlação moderada. 


\begin{tabular}{c|c|c|c}
$\begin{array}{c}\text { DIAS EM } \\
\text { SALA }\end{array}$ & NÃO & SIM & $\begin{array}{c}\text { TOTAL DE } \\
\text { VOLUNTÁRIOS }\end{array}$ \\
\hline $\mathbf{1}$ & 0 & $\mathbf{2}$ & $\mathbf{2}$ \\
2 & 1 & 2 & 3 \\
3 & 2 & 4 & 6 \\
4 & 2 & 5 & 7 \\
$\mathbf{5}$ & 6 & $\mathbf{1 0}$ & $\mathbf{1 6}$ \\
6 & 2 & 0 & 2 \\
TOTAL & 13 & 23 & 36 \\
\hline
\end{tabular}

\section{DISCUSSÃO}

Foi evidenciado um bom nível de QV geral por parte dos docentes fisioterapeutas participantes desta pesquisa em todos os domínios abordados pela SF-36. Com o nível de significância de 5\%, os domínios de destaque da SF-36 com maior impacto sobre a qualidade de vida dos docentes fisioterapeutas participantes deste estudo foram "Capacidade Funcional", "Dor", "Limitação por Aspectos Físicos" e "Vitalidade". A variável "Limitações por Aspectos Emocionais" ficou fora do intervalo de confiabilidade do estudo, alcançando o nível de 6\%, porém obteve um escore elevado e próximo aos que foram considerados significantes, mostrando que essa variável pode influenciar os domínios supracitados.

Apesar do impacto negativo de alguns domínios avaliados, os quais podem influenciar na Qualidade de Vida (QV) dos docentes fisioterapeutas, não significa que os indivíduos abordados interpretem estes dados como prejuízo do seu bem-estar geral. Por outro lado, alguns profissionais podem apresentar escores excelentes em relação aos domínios abordados em determinados instrumentos padronizados para a avaliação da QV (a exemplo da SF-36), significando uma boa qualidade de vida, e possuírem a sensação de fracasso. Isso acontece porque a noção que cada pessoa tem do que é QV é única, intransferível e independe dos conceitos pré-estabelecidos pela sociedade.

$\mathrm{O}$ conceito de QV vem sendo, nos tempos atuais, erroneamente empregado, sendo muitas vezes usado como sinônimo de saúde, e não como domínios complementares, fato que influencia diretamente nos resultados das pesquisas científicas. ${ }^{(1)}$ Por este motivo houve a preocupação em criar um instrumento para avaliação dos aspectos pessoais e profissionais dos entrevistados relacionados à QV, 
supracitado como "Questionário Semiestruturado", bem como de utilizar um questionário padronizado que pudesse avaliar a perspectiva da população sobre a própria QV, diferente de utilizar apenas a ótica o observador, mas considerar e respeitar a subjetividade relacionada à temática.

Para cumprir o objetivo do presente estudo de avaliar a QV dos docentes fisioterapeutas da cidade do Salvador/Bahia, foram incluídos 36 profissionais atuantes em sala de aula no momento da coleta de dados. Desses, 52,8\% eram mulheres e 47,2\% eram homens; dados que corroboram com a literatura, mostrando maior quantidade de profissionais do gênero feminino na docência e na fisioterapia. Esse percentual pode ser explicado pelo desenvolvimento da sociedade, com a crescente inserção do sexo feminino no mercado de trabalho, além da perspectiva histórica de que as mulheres apresentam maior dom de educar, seja dentro ou fora do ambiente doméstico. Em meados do século XX, a realidade construída acerca do papel da mulher na sociedade se relacionava ao ambiente doméstico, associado ao casamento e à maternidade, onde a docência se apresentava como a única saída para as mulheres que desejavam ter outras atividades. ${ }^{(12-15)}$ Além disso, a profissão de fisioterapia, em linhas gerais, apresenta como perfil o maior número de profissionais do gênero feminino, o que justifica a predominância desta amostra. ${ }^{(16,17)}$

Do total de voluntários, 30,6 \% encaixam-se na faixa etária entre 31-35 anos, sendo a média de 36,2 anos. Em relação ao tempo de formado em Fisioterapia, a média foi de 12,8 anos, sendo que o tempo médio de atuação desses profissionais em sala de aula foi de 8,5 anos. Esses dois últimos dados podem ser justificados pelo tempo de vida da profissão, que é considerada recente. O Decreto de Lei que transformou a Fisioterapia de curso técnico para curso de nível superior foi sancionado no dia 13 de Outubro de 1969. No entanto, o crescimento do número de cursos na área só eclodiu no ano de 1997, resultando então, em um maior número de profissionais formados a partir de então. ${ }^{(18,19)}$

Dos 36 voluntários, 72,2\% relataram não apresentar doença muscular ou óssea diagnosticada, porém vinte e três voluntários, que correspondem a $63,9 \%$ da população estudada, apresentaram dor e/ou desconforto osteomuscular. Das doenças musculares diagnosticadas, a Hérnia de Disco foi a que predominou com 8,4\%. Dos desconfortos mais referidos, a região do ombro associada à coluna lombar predominou com $17,4 \%$, 
seguida pela coluna lombar, isoladamente, com 13\%. Pode-se observar que as áreas álgicas referidas pela população avaliada localizam-se na musculatura antigravitacional. Por esse motivo, acredita-se que essas dores estejam diretamente ligadas à postura adotada pelo docente, o qual permanece longos períodos do dia em ortostatismo, além de utilizar demasiadamente os membros superiores. Com relação aos profissionais que também atuam fora da sala de aula, os mesmos mantém determinadas posturas durante as sessões terapêuticas com o paciente, como por exemplo, a ortostase associada a flexões de tronco, posturas mantidas para execução das terapias manuais, transferência de paciente dependente, entre outros, que contribuem para o desenvolvimento de algias e disfunções musculoesqueléticas, como pode ser visto em outros trabalhos.

A título de aproximação temática, Carvalho e Alexandre ${ }^{(20)}$ fizeram um estudo no qual foi encontrada uma associação entre a presença de dor na região dos ombros em docentes do ensino fundamental e a faixa etária dos voluntários (30-39 anos). Para isso, foram pesquisados 212 professores do ensino fundamental da rede estadual São Paulo, utilizando como instrumento de pesquisa o Questionário Nórdico de Sintomas Osteomusculares. Os resultados encontrados de maior dor em ombro podem ser justificados pelo nível de produtividade dos indivíduos jovens e a elevada exposição aos fatores de risco, uma vez que estes assumem um número maior de responsabilidades e tarefas, sobrecarregando as estruturas corporais. Além disso, a própria dinâmica da sala de aula favorece o aparecimento dos sintomas do ombro. Outro dado referente do trabalho supracitado é a prevalência de dor na região lombar, a qual apresentou $63,1 \%$ de incidência.

Esses percentuais demonstrados no estudo supracitado, exclusivo de docentes, podem ser utilizados para a comparação com os resultados encontrados na presente pesquisa, onde houve também uma maior incidência da associação da sintomatologia álgica no ombro e na lombar, bem como desta última isoladamente. Ao considerar ainda a docência associada ao exercício profissional da fisioterapia, torna-se mais importante esse achado, uma vez que o fisioterapeuta utiliza basicamente o corpo como ferramenta para o tratamento do paciente, o que sugere a necessidade de pesquisas e orientações, buscando a prevenção.

Em relação ao exercício profissional do fisioterapeuta, Giglio ${ }^{(17)}$ buscou analisar queixas osteomusculares entre tais profissionais que trabalham no INCA - Instituto 
Nacional de Câncer, na cidade do Rio de Janeiro. Para tal, utilizou o Questionário Nórdico de Sintomas Osteomusculares, contou com a participação de 70 voluntários, sendo a maioria do sexo feminino (84\%), com uma média de 36,2 anos, e carga horária predominantemente de 30 horas. Os mesmos apresentaram a região lombar como a mais acometida tanto em doze meses quanto em sete dias (45\% e $29,1 \%$ respectivamente), seguida pela região dos ombros $(35,1 \%$ e $21,6 \%$, respectivamente). Isso pode ser atribuído às posturas adotadas pelos profissionais durante o atendimento dos pacientes. Posturas e movimentos sustentados e requeridos durante a terapia são a base do trabalho, visto que os pacientes apresentam diferentes níveis de dependência. A manutenção dos membros superiores elevados, suspensão de carga, agachamento, rotação da coluna vertebral associada à flexão, são constantes durante a sessão terapêutica.

Num estudo de revisão de literatura realizado por Carregaro, Trelha e Mastelari, ${ }^{(5)}$ os mesmos afirmam que de 60 a $80 \%$ de todas as pessoas sentirão dor na região lombar em algum momento das suas vidas. Trazem ainda que a causa é de origem multifatorial, e diminui a capacidade funcional dos indivíduos com menos de 45 anos, independente da profissão. Focando na fisioterapia, os autores Siqueira, Cahú e Vieira, ${ }^{(21)}$ avaliaram 56 participantes, devidamente credenciados ao CREFITO - 1, atuando nas áreas de Traumatologia/Ortopedia ou Fisioterapia Neurológica nas clínicas da cidade do Recife. Os voluntários responderam ao Questionário de Sintomas Osteomusculares da Coluna Lombar e a Escala Visual Numérica (EVN), e os pesquisadores encontraram a ocorrência de lombalgia em 78,58\% dos participantes. A alta concordância entre os autores com relação aos sintomas álgicos na lombar está diretamente associada, como já foi citado anteriormente, à demanda física da profissão, constituída pela sustentação de carga e alta repetição de movimentos corporais no atendimento dos pacientes, na maioria das vezes.

Essa realidade pode ser vista fora do território brasileiro, como foi feito no estudo de Shehab et al. ${ }^{(16)}$ no Kuwait, no qual contaram, com a participação de 100 voluntários de diferentes áreas de atuação. A maioria dos voluntários foi constituída do sexo feminino, sendo que aqueles que trabalhavam nas áreas de Ortopedia $(24,34 \%)$ e Neurologia $(17,24)$ foram os que mais se queixaram de lombalgia. 
Com relação às áreas de atuação encontradas, o presente estudo obteve maior número de profissionais atuantes nas áreas de Gestão $(13,9 \%)$ e Outros (Terapias Holísticas, Acupuntura, RPG - Reeducação Postural Global, Saúde da Mulher, Saúde na Comunidade, Ortotrauma e Geriatria) com 46,8\%, além dos docentes (100\%), o que difere dos achados dos estudos anteriores. Esses dados podem ser justificados pela diferença da metodologia empregada quando comparada aos estudos citados anteriormente, onde distribuíram os instrumentos para a coleta de dados em diferentes locais como hospitais, clínicas, escolas e comunidade, com o objetivo de abordar fisioterapeutas das mais diversas áreas de atuação. Já o presente estudo abordou os fisioterapeutas que estivessem lecionando no momento da pesquisa, independente dos mesmos estarem atuando ou não em outros locais.

Ao analisar os resultados da SF-36, notou-se que quatro domínios, dos oito abordados pela escala, entraram no índice de significância $(\mathrm{p}<0,05)$ de forma positiva quando comparados com a variável "Dor e/ou Desconforto Osteomuscular", sendo eles a Capacidade Funcional, Dor, Limitação por Aspectos Físicos e Vitalidade.

Dos 36 participantes da pesquisa, 17 (47,2\%) apresentaram pontuação de 100 no domínio Capacidade Funcional, sendo que o menor escore obtido pelos voluntários foi de 65. Isso significa que todos os voluntários conseguem realizar as suas atividades de forma satisfatória, baseada na sua própria visão, independente das queixas álgicas. Este dado corrobora com o estudo de Rocha e Fernandes, ${ }^{(7)}$ realizado na cidade de Jequié BA, com 91 professores do ensino fundamental. Os autores consideraram no seu estudo, o domínio Capacidade Funcional (CF) como "regular" ao nível dos 65 de pontuação atingida pelos participantes, diferentemente do nível de corte adotado no presente estudo. Sabe-se que não há consenso na literatura acerca de "classificações" do escore obtido pelo voluntariado através da SF-36. Sendo assim, de acordo com a validação da escala supracitada, na qual Ciconelli et al. ${ }^{(10)}$ trazem que zero corresponde ao "pior estado de saúde" e 100 ao "melhor estado de saúde", e que a população do estudo de Rocha e Fernandes ${ }^{(7)}$ atingiu na CF $(65,71)$; escore que pode ser considerado como "melhor estado de saúde", conforme as especificações adotadas no presente trabalho.

No quesito Dor, dez voluntários $(27,8 \%)$ obtiveram 100 pontos, dois $(5,6 \%) 41$ e um $(2,8 \%), 10$. Apesar da maioria ter conseguido a pontuação máxima da escala, 63,9\% da amostra relataram ter algum tipo de dor ou desconforto osteomuscular. Cogo et al. ${ }^{(22)}$ 
descrevem a dor como um sinal de que algo está errado no funcionamento do corpo, e esse sintoma afeta a pessoa globalmente, restringindo total ou parcialmente, a capacidade funcional e o seu relacionamento com outros indivíduos, gerando estresse, ansiedade e medo. Porém, nota-se que apesar das dores apresentadas pelos profissionais do presente estudo, os mesmos continuam as suas atividades, ou por questões socioeconômicas ou porque a dor não chega a ser tão intensa a ponto de impactar negativamente na QV, o que demanda maiores estudos de campo para abordar, elucidar e compreender esta realidade identificada.

Observa-se, portanto, que apesar do grande número de relatos de dores e/ou desconfortos osteomusculares encontrados nesta pesquisa, os marcadores de QV referentes a tal domínio não foram afetados de acordo com escala utilizada nesta avaliação. Pode-se inferir que os voluntários apresentam um alto nível de satisfação pessoal e profissional, e/ou realizam atividades que minimizam tais sintomas. Outro ponto a ser considerado é que os profissionais abordados são capacitados para tratar tais doenças do sistema musculoesquelético, na modalidade de autocuidado; ou então a referida dor não tenha sido significante a ponto de impactar na capacidade funcional dos participantes. No caso da intensidade da dor, não foi a intenção deste estudo avaliar de forma específica este quesito.

Na Limitação por Aspectos Físicos 23 participantes (63,9\%) obtiveram escore de 100 na SF-36, oito $(22,2 \%) 75$, um $(2,8 \%)$ 50, com “melhor estado de saúde". Quatro participantes $(11,1 \%)$ obtiveram pontuação abaixo de 50 , o que pode repercutir negativamente sobre o estado de saúde do indivíduo. O estudo de Rocha e Fernandes ${ }^{7}$ obteve resultados semelhantes, onde a população estudada obteve o escore de 61,53 para a QV, porém os autores consideraram este resultado como "regular".

No domínio "Vitalidade", que avalia o sentimento de energia, de vigor e força, os voluntários do presente estudo atingiram uma pontuação que pode ser analisada como "melhor estado de saúde", onde obtiveram escore máximo de 85 na questão. Apenas cinco $(13,9 \%)$ participantes obtiveram pontuações que indicam "pior estado de saúde". O domínio abordado difere dos achados da literatura, onde diversos autores trazem pontuações baixas relacionadas à vitalidade, e justificam este fato como consequência do desgaste progressivo que todo e qualquer trabalho pode gerar. ${ }^{(7,23,24)}$ 
A pontuação máxima referente ao domínio "Limitações por Aspectos Emocionais" foi obtida por 27 voluntários (75\%). Em contrapartida, três voluntários $(8,3 \%)$ zeraram tais questões, e cinco $(13,9 \%)$ conseguiram a pontuação de 33,30 , o que significa "pior estado de saúde". Apesar dos resultados referentes a este domínio terem se localizado na margem da significância proposta para este estudo, sabe-se que o mesmo pode influenciar ativamente os domínios que foram significantes nesta pesquisa (Dor, Capacidade Funcional, Vitalidade e Limitação Por Aspectos Físicos), seja de forma positiva ou negativa. Cogo et al. ${ }^{(2)}$ trazem em seu estudo que os fatores emocionais podem ser determinantes para uma boa QV dos docentes fisioterapeutas, uma vez que essa população demonstra alto grau de satisfação quando obtém o reconhecimento pelo trabalho realizado, e consideram este reconhecimento como fonte de prazer. Assim, conseguem amenizar sentimentos de frustração ao alcançar os seus objetivos.

Ao correlacionar "Dor e/ou Desconforto Osteomuscular" com as demais variáveis abordadas no presente estudo, pôde-se observar comprometimento diretamente proporcional apenas com a quantidade de dias que os docentes estão na sala de aula, já que esta foi a única correlação com $P$ significante, sendo o valor obtido de $P=0,351$. Essa correlação também foi observada por Panzeri, ${ }^{(25)}$ em um estudo transversal, que analisou os sintomas musculoesqueléticos e a qualidade de vida de 157 professores do ensino fundamental das escolas Estaduais e Municipais de uma cidade do interior de São Paulo, através da SF-36 e do Questionário Nórdico. Essa ligação entre as variáveis justifica-se pela grande variedade de atividades realizadas sem intervalo para descanso ou com tempo mínimo para tal, sobrecarregando as estruturas mentais e as corporais, tanto pela "interação social" com diversas pessoas quanto pela manutenção da postura por tempo prolongado. Isso pode intensificar-se ainda mais quando associada à prática de outra atividade profissional.

\section{CONSIDERAÇÕES FINAIS}


Diante do exposto, o presente estudo mostrou, de forma geral, um bom nível de Qualidade de Vida (QV) por parte dos docentes fisioterapeutas em todos os domínios abordados pela Escala SF-36, apesar das algias musculares relatadas pelos participantes, divergindo do que era esperado, bem como de parte dos achados da literatura.

A significância apontou os domínios "Capacidade Funcional”, "Dor", Vitalidade" e "Limitações por Aspectos Físicos" como mais influentes na QV, sendo que as relações feitas entre eles e as "Dores e/ou Desconfortos Oesteomusculares" não se mostraram diretamente proporcionais. A única correlação proporcional foi "Dor e/ou Desconforto Oesteomuscular x Dias em sala", na qual quanto mais dias o docente está em sala, mais ele refere dor. Com base nesses dados, é importante o conhecimento das possíveis repercussões da prática profissional e docente sobre a QV, de forma a permitir ações de sensibilização, prevenção, medidas ergonômicas e de valorização profissional no contexto multidimensional.

O presente estudo trouxe como uma das limitações, o pouco ou nenhum tempo disponibilizado por alguns voluntários para o preenchimento dos instrumentos utilizados na pesquisa, fator que influenciou diretamente no número da amostra. Entretanto, este fato não impactou no aspecto qualitativo das respostas. Além disso, por se tratar de um estudo transversal, não é possível generalizar os dados, até mesmo porque se trata de uma população específica, avaliada em um único momento. Sugere-se então, a realização de novos estudos com um maior tamanho de amostra, partindo de uma amostragem aleatória, com metodologia de caráter longitudinal para melhor conhecimento dos fatores relacionados à QV dos docentes fisioterapeutas.

\section{REFERÊNCIAS}

1. Ministério da Educação e Cultura. Secretaria de Educação Superior [homepage na internet]. Apresentação [acesso em 03 jul 2011]. Disponível em:

http://portal.mec.gov.br/index.php?option=com_content\&view=article\&id=287\&Itemid $=818$

2. Navarro VL. O trabalho e a saúde do trabalhador na indústria de calçados. São Paulo Perspect. 2003;17(2):32-41.

3. COFFITO - Conselho Federal de Fisioterapia e Terapia Ocupacional [homepage na internet]. Fisioterapia: definições e área de atuação [acesso em 07 set 2011]. Disponível em: http://www.coffito.org.br/publicacoes/pub_view.asp?cod=1007\&psecao=9 
4. Fernandes MH, Rocha VM, Costa-Oliveira AGR. Fatores associados à prevalência de sintomas osteomusculares em professores. Rev. Salud Pública. 2009;11(2): 256-267.

5. Carregaro RL, Trelha CS, Mastelari HJZ et al. Distúrbios osteomusculares relacionados ao trabalho em fisioterapeutas: revisão da literatura. Fisioter pesqui. 2006;12(3).

6. Martins DA. Considerações sobre a qualidade de vida no trabalho e o estresse ocupacional [acesso em 10 set 2011]. Disponível em:

http://www.fef.unicamp.br/departamentos/deafa/qvaf/livros/foruns_interdisciplinares_sa ude/evolucao/evolucao_cap14.pdf

7. Rocha VM, Fernandes MH. Qualidade de vida de professores do ensino fundamental: uma perspectiva para a promoção da saúde do trabalhador. J Bras Psiquiatr. 2008;57(1): 23-27.

8. Penteado RZ; Pereira IMTB. Qualidade de vida e saúde vocal de professores. Rev. saúde pública. 2007;41(2): 236-43.

9. Fleck MPA et al. Desenvolvimento da versão em português do instrumento de avaliação de qualidade de vida da OMS (WHOQOL-100). Rev. Bras. Psiquiatr. 1999; 21(1):19-28.

10. Ciconelli RM et al. Tradução para a língua portuguesa e validação do questionário genérico de avaliação da qualidade de vida SF-36 (Brasil SF-36). Rev. bras. reumatol. 1999; 39(3).

11. Seidl EMF, Zannon CMLC. Qualidade de vida e saúde: aspectos conceituais e metodológicos. Cad. saúde pública. 2004;20(2): 580-588.

12. Delcor NS et al. Condições de trabalho e saúde dos professores da rede particular de ensino de Vitória da Conquista, Bahia, Brasil. Cad. saúde pública. 2004;20(1):187196.

13. Servilha EAM. Estresse em professores universitários na área de fonoaudiologia. Rev. ciênc. méd. 2005;14(1): 43-52.

14. Oliveira ERA et al. Gênero e qualidade de vida percebida: estudo com professores da área de saúde. Ciênc. saúde coletiva. 2012;17(3):741-747.

15. Aragão M, Kreutz L. A docência na educação Infantil: entre o dom e a maternidade. InterMeio: revista do Programa de Pós-Graduação em Educação. 2010; 16(32):13-26.

16. Shehab D et al. Prevalence of Low Back Pain among Physical Therapists in Kuwait. Med Princ Pract. 2003:224-230.

17. Giglio AG. Estudo das queixas osteomusculares entre fisioterapeutas em um hospital oncológico [dissertação]. Brasília: Universidade de Brasília, 2010. 
18. Bispo Junior JP. Formação em fisioterapia no Brasil: reflexões sobre a expansão do ensino e os modelos de formação. Hist. ciênc. saúde-Manguinhos. 2009; 16(3): 655-68.

19. Salmória JG, Camargo WA. Uma aproximação dos signos. Fisioterapia e Saúde aos Aspectos Humanos e Sociais. Saúde Soc. 2008;17(1):73-84.

20. Carvalho AJFP, Alexandre NMC. Sintomas osteomusculares em professores do ensino fundamental. Rev. bras. fisioter. 2006;10(1).

21. D’Ávila LS, Sousa GAF, Sampaio RF. DMRT em fisioterapeutas da Rede SUSBH. Revista bras. fisioter. 2005; 9(2): 219-225.

22. Siqueira GR, Cahú FGM, Vieira RAG. Ocorrência de lombalgia em fisioterapeutas da cidade de Recife, Pernambuco. Revista bras. fisioter. 2008;12(3): 222-227.

23. Cogo LLR et al. Perfil da qualidade de vida dos fisioterapeutas docentes do curso de fisioterapia da Universidade do Vale do Itajaí. Revista Contexto \& Saúde. 2011:367374.

24. Silva MA. Avaliação da qualidade de vida de professores do ensino fundamental: influência das variáveis sócio-demográficas [dissertação]. Goiânia: Universidade Federal de Goiás, 2011.

25. Panzeri AJF. Sintomas osteomusculares e qualidade de vida em professores do ensino fundamental [dissertação]. São Paulo: Universidade Estadual de Campinas, 2011. 